\title{
CRIME DE ABORTO E INTERRUPÇÃO VOLUNTÁRIA DA GESTAÇÃO NO PRIMEIRO TRIMESTRE: ANÁLISE DA DECISÃO DO SUPREMO TRIBUNAL FEDERAL NO HABEAS CORPUS 124.306
}

CRIME OF ABORTION AND VOLUNTARY INTERRUPTION OF PREGNANCY IN THE FIRST QUARTER: ANALYSIS OF THE DECISION OF THE SUPREME FEDERAL COURT IN THE HABEAS CORPUS 124.306

Wilson Steinmetz ${ }^{1}$ Janaína Reckziegel ${ }^{2}$

Resumo: Neste estudo analisa-se a decisão da Primeira Turma do Supremo Tribunal Federal, segundo a qual é inconstitucional a criminalização do aborto na hipótese de interrupção voluntária de gestação no primeiro trimestre. Apresenta-se uma síntese dos aspectos fáticos do caso e dos fundamentos normativos da decisão. Ao final, fazem-se uma apreciação crítica dos fundamentos normativos adotados pelo Supremo Tribunal Federal e considerações sobre os desdobramentos da decisão nos planos judicial e político-legislativo.

Palavras-chave: Gestação. Interrupção voluntária. Crime. Direitos fundamentais da mulher. Princípio da proporcionalidade.

\begin{abstract}
This study aims at analyzing the decision of the Federal Supreme Court according to which the criminalization of abortion is unconstitutional in the hypothesis of voluntary interruption of pregnancy in the first trimester. A summary of the factual aspects of the case and the normative grounds of the decision is presented. In the end, a critical assessment of the normative foundations adopted by the Federal Supreme Court and considerations about the consequences in the plan judicial and political are made.
\end{abstract}

Keywords: Pregnancy. Voluntary interruption. Crime. Fundamental rights of women. Proportionality principle.

\footnotetext{
Doutor e Mestre em Direito pela Universidade Federal do Paraná; Professor no Programa de Pós-Graduação em Direito da Universidade do Oeste de Santa Catarina e no Programa de Pós-Graduação em Direito da Universidade de Caxias do Sul; Rua Francisco Getúlio Vargas, 1130, Petrópolis, 95070-560, Caxias do Sul, Rio Grande do Sul, Brasil; wilson.steinmetz@gmail. com

2 Doutora em Direitos Fundamentais e Novos Direitos pela Universidade Estácio de Sá; Mestre em Direito pela Universidade de Caxias do Sul; Professora Universitária e Pesquisadora do Programa de Pós-Graduação em Direito da Universidade do Oeste de Santa Catarina; janaina.reck@gmail.com
} 


\section{Introdução}

No segundo semestre de 2016, logo após o recesso de julho, a Primeira Turma do Supremo Tribunal Federal (STF) reuniu-se para julgar mais um dos inúmeros habeas corpus impetrados e que tramitam nas instâncias de deliberação dessa corte judicial (duas turmas e Plenário). À primeira vista, era apenas mais um caso, entre muitos, em que pacientes pedem a revogação de prisão preventiva para responder à ação penal em liberdade. Os pacientes já eram réus em processo penal instaurado com fundamento nos arts. 288 e 126 do Código Penal, em concurso material por quatro vezes. Tratava-se, então, de verificar se estavam presentes os supostos fáticos do art. 312 do Código de Processo Penal $^{3}$ que fundamentam a prisão cautelar. A rigor, no plano mais imediato, estava-se ante um caso de jurisdição ordinária: analisar fatos e decidir com base em normas infraconstitucionais.

Ao final do julgamento, foi concedida a ordem pedida não somente com fundamento na ausência dos elementos que justificam a prisão preventiva, mas também com o fundamento de que, em interpretação conforme a Constituição, é inconstitucional a incidência dos arts. 124 e 126 do Código Penal nos casos de interrupção voluntária de gestação no primeiro trimestre. Pela primeira vez, o Supremo Tribunal Federal, por meio de uma de suas instâncias e em controle incidental de constitucionalidade, adotou a tese, já assentada em alguns países por meio de decisão judicial e em outros por meio de lei, de que a criminalização do aborto voluntário no primeiro trimestre viola direitos fundamentais da mulher.

Neste estudo do caso decidido no Habeas Corpus 124.306 (BRASIL, 2016) põem-se em evidência os elementos constitutivos do segundo - e, por que não dizer, inesperado - fundamento para a concessão da ordem que revogou a prisão preventiva dos pacientes:

[...] é preciso conferir interpretação conforme a Constituição aos próprios arts. 124 a 126 do Código Penal - que tipificam o crime de aborto - para excluir do seu âmbito de incidência a interrupção voluntária da gestação efetivada no primeiro trimestre. A criminalização, nessa hipótese, viola diversos direitos fundamentais da mulher, bem como o princípio da proporcionalidade (BRASIL, 2016, p. 1).

Esse fundamento (tese) é o elemento novo na jurisprudência do Supremo Tribunal Federal em matéria de aborto e dos direitos fundamentais que estão em jogo no caso da prática do aborto. À primeira vista, é apenas uma isolada decisão do STF, sem efeitos erga omnes e vinculantes para as demais instâncias do Poder Judiciário, para o Ministério Público e para a Polícia Judiciária. No entanto, essa decisão tem o potencial de recolocar o tema da descriminalização do aborto na agenda política e jurídica do País. Essa decisão já serviu de inspiração para o Partido Socialismo e Liberdade (PSOL)

\footnotetext{
3 Art. 312. A prisão preventiva poderá ser decretada como garantia da ordem pública, da ordem econômica, por conveniência da instrução criminal, ou para assegurar a aplicação da lei penal, quando houver prova da existência do crime e indício suficiente de autoria.

Parágrafo único. A prisão preventiva também poderá ser decretada em caso de descumprimento de qualquer das obrigações impostas por força de outras medidas cautelares (art. 282, \4 $4^{\circ}$ ) (BRASIL, 2011).
} 
ajuizar uma Arguição de Descumprimento de Preceito Fundamental (ADPF 442) na qual pede ao STF que, com efeitos erga omnes e vinculantes, "declare a não recepção parcial dos art. 124 e 126 do Código Penal, para excluir do seu âmbito de incidência a interrupção da gestação induzida e voluntária realizada nas primeiras 12 semanas." (BRASIL, 2017, grifo nosso). ${ }^{4}$

Inicialmente, apresenta-se uma síntese dos aspectos fáticos do caso e dos fundamentos normativos da decisão. Ao final, fazem-se uma apreciação crítica dos fundamentos normativos adotados pelo Supremo Tribunal Federal e considerações sobre os desdobramentos da decisão nos planos judicial e político-legislativo.

\section{Fatos do caso}

Os pacientes Edilson dos Santos e Rosemere Aparecida Ferreira, que mantinham clínica de aborto, foram presos em flagrante em 14 de março de 2013 pela suposta prática dos crimes previstos nos arts. $288^{5}$ e $126^{6}$ do Código Penal. Em 21 de março de 2013, o juízo da $4^{\text {a }}$ Vara Criminal da Comarca de Duque de Caxias, RJ, concedeu a liberdade provisória aos pacientes com o argumento de que "as infrações imputadas são de médio potencial ofensivo, com penas relativamente brandas, permitindo que, em caso de condenação, sejam aplicadas sanções conversíveis em penas restritivas de direitos ou, no máximo, a serem cumpridas em regime aberto." A denúncia criminal foi recebida em 04 de abril de 2013.

O Ministério Público do Estado do Rio de Janeiro recorreu da decisão (Recurso em Sentido Estrito n. 0065502-27.2013.8.19.0000), pedindo a prisão preventiva para garantir a ordem pública e assegurar a aplicação da lei penal. $\bigcirc$ recurso foi provido pela $4^{\text {a }}$ Câmara Criminal do Tribunal de Justiça do Estado do Rio de Janeiro em 25 de fevereiro de 2014, com a consequente expedição de mandados de prisão contra os pacientes.

Após o indeferimento por unanimidade de liminar em habeas corpus impetrado no Superior Tribunal de Justiça (Sexta Turma) (BRASIL, 2014), a defesa impetrou habeas corpus no Supremo Tribunal Federal. Em 08 de dezembro de 2014, o ministro Marco Aurélio, primeiro relator designado,

\footnotetext{
4 O PSOL pede "a confirmação da medida liminar e, no mérito, a procedência da presente Ação de Descumprimento de Preceito Fundamental para que, com eficácia geral e efeito vinculante, esta Suprema Corte declare a não recepção parcial dos art. 124 e 126 do Código Penal, para excluir do seu âmbito de incidência a interrupção da gestação induzida e voluntária realizada nas primeiras 12 semanas, por serem incompatíveis com a dignidade da pessoa humana e a cidadania das mulheres e a promoção da não discriminação como princípios fundamentais da República, e por violarem direitos fundamentais das mulheres à vida, à liberdade, à integridade física e psicológica, à igualdade de gênero, à proibição de tortura ou tratamento desumano ou degradante, à saúde e ao planejamento familiar, de modo a garantir às mulheres o direito constitucional de interromper a gestação, de acordo com a autonomia delas, sem necessidade de qualquer forma de permissão específica do Estado, bem como garantir aos profissionais de saúde o direito de realizar o procedimento." (ADPF 442, petição inicial) (BRASIL, 2017).

5 Associação Criminosa. Art. 288. Associarem-se 3 (três) ou mais pessoas, para o fim específico de cometer crimes: Pena - reclusão, de 1 (um) a 3 (três) anos (BRASIL, 2013).

6 Aborto provocado por terceiro. Art. 126 - Provocar aborto com o consentimento da gestante: Pena - reclusão, de um a quatro anos.

Parágrafo único. Aplica-se a pena do artigo anterior, se a gestante não é maior de quatorze anos, ou é alienada ou débil mental, ou se o consentimento é obtido mediante fraude, grave ameaça ou violência.
} 
entendeu que não subsistiam no caso os fundamentos do art. 312 do Código de Processo Penal e deferiu a liminar para que os pacientes aguardassem o julgamento da ação penal em liberdade. No julgamento do mérito pela Primeira Turma do Supremo Tribunal Federal, o relator, ministro Marco Aurélio, votou pela concessão definitiva da ordem de habeas corpus. Após o voto do relator, o ministro Luís Roberto Barroso pediu vista dos autos. Em 29 de novembro de 2016, conforme o Extrato da Ata, prolatou-se a seguinte decisão: "Por maioria de votos, a Turma não conheceu da impetração, mas concedeu a ordem, de ofício, nos termos do voto do Senhor Ministro Luís Roberto Barroso, Presidente e Redator para o acórdão, vencido o Senhor Ministro Marco Aurélio, Relator, que a concedia." (BRASIL, 2014).

\section{Questão jurídica}

Desde o primeiro grau de jurisdição até a decisão da Sexta Turma do Superior Tribunal de Justiça, em momento algum se postulou, discutiu ou examinou a inconstitucionalidade ou a não recepção em tese das normas penais aplicáveis ao caso, ou se postulou, discutiu ou examinou a hipótese de uma interpretação de normas penais conforme a constituição. A questão jurídica e a pretensão dos pacientes referiam-se à materialização, no caso concreto, das hipóteses que justificam a prisão preventiva (Código de Processo Penal, art. 312). Para os pacientes e para o juízo de primeiro grau, a resposta era negativa. Para o Ministério Público, para o Tribunal de Justiça do Estado do Rio do Janeiro e também para o Superior Tribunal de Justiça, a resposta era afirmativa. A questão jurídica do caso estava definida e delimitada como uma questão estritamente de direito processual penal.

No entanto, a partir do voto-vista do ministro Luís Roberto Barroso, à dimensão processual penal da questão jurídica adicionou-se uma dimensão constitucional substantiva controversa e de grande repercussão: o exame da (in)constitucionalidade da incidência de normas penais (Código Penal, arts. 124 e 126) que criminalizam o aborto no caso de interrupção voluntária da gestação no primeiro trimestre.

Ao final, por maioria, a Primeira Turma do Supremo Tribunal Federal concedeu a ordem de ofício, ${ }^{7}$ afirmando que não somente estavam ausentes os requisitos para a decretação da prisão preventiva dos pacientes réus, mas também, usando a técnica da interpretação conforme a Constituição, que é inconstitucional a incidência do tipo penal do aborto no caso de interrupção voluntária da gestação no primeiro trimestre.

\footnotetext{
7 Por maioria de votos, a Turma não conheceu da impetração, mas concedeu a ordem, de ofício, nos termos do voto do ministro Luís Roberto Barroso: "Inicialmente, verifico que se trata de habeas corpus, substitutivo do recurso ordinário constitucional, impetrado contra acórdão unânime da Sexta Turma do Superior Tribunal de Justiça que não conheceu do HC 290.341/ RJ. Nos termos da jurisprudência majoritária desta Primeira Turma (HC 109.956, Rel. Min. Marco Aurélio; HC 128.256, Rel. Min. Rosa Weber), nessa hipótese, o processo deve ser extinto, sem resolução do mérito, por inadequação da via processual. Nada obstante isso, em razão da excepcional relevância e delicadeza da matéria, passo a examinar a possibilidade de concessão da ordem de ofício." (Voto-vista do ministro Luís Roberto Barroso) (BRASIL, 2016, p. 11).
} 


\section{Fundamentos da decisão}

Segundo a decisão da Primeira Turma, a criminalização da interrupção voluntária da gravidez no primeiro trimestre contraria diversos direitos fundamentais: a autonomia da mulher, a integridade física e psíquica da gestante, direitos sexuais e reprodutivos da mulher e o princípio da igualdade.

O voto-vista do ministro Luís Roberto Barroso estabeleceu os pontos centrais da questão e por isso tornou-se condutor da decisão da Primeira Turma e certamente servirá de referência futura para os debates, especialmente para a decisão que o Supremo Tribunal Federal tomará no julgamento da ADPF 442.

O ministro Luís Edson Fachin acompanhou integralmente o voto do ministro Luís Roberto Barroso em todos os fundamentos. Embora tenha apresentado voto concorrente, a ministra Rosa Webber também concordou com todos os fundamentos expostos pelo ministro Luís Roberto Barroso. A ministra, porém, explorou casos e posições da jurisprudência comparada.

Assim, para este estudo, elege-se como fio condutor o voto do ministro Luís Roberto Barroso.

\subsection{Premissa}

No ponto de partida do controverso debate sobre o aborto está o problema do status jurídico do embrião na fase inicial da gestação. Há ao menos duas teses antagônicas e inconciliáveis. Uma tese diz que há vida desde a concepção ou fecundação. A outra diz que não há vida antes da formação do sistema nervoso central, fenômeno fisiológico que ocorre após o terceiro mês da gestação.

A Constituição Federal institui o direito à vida como direito fundamental de resistência a intervenções estatais injustificadas e como direito fundamental à proteção estatal contra violação ou ameaças de violação de terceiros (art. $5^{\circ}$, caput). A Constituição, porém, não define o momento inicial da vida a ser respeitada e protegida. Na visão do ministro Luís Roberto Barroso, não há solução jurídica para essa questão. A solução depende de escolhas apoiadas em fundamentos religiosos ou filosóficos.

Sem se posicionar categoricamente sobre se há vida ou não a ser protegida desde a concepção ou fecundação, o ministro Luís Roberto Barroso assume como premissa fática de toda a sua argumentação que "[...] não há qualquer possibilidade de o embrião subsistir fora do útero materno nesta fase [primeiro trimestre] de sua formação. Ou seja: ele dependerá integralmente do corpo da mulher." (BRASIL, 2016, p. 17).

A criminalização da interrupção voluntária da gestação no primeiro trimestre viola direitos fundamentais das mulheres. Assim, "Coerentemente, se a conduta da mulher é legítima, não há sentido em se incriminar o profissional de saúde que a viabiliza." (BRASIL, 2016, p. 16). 


\subsection{Direitos fundamentais da mulher gestante}

A criminalização da interrupção voluntária da gestação no primeiro trimestre viola a autonomia da mulher garantida pelo direito fundamental de liberdade e pelo princípio da dignidade da pessoa humana. A autonomia é expressão concreta do direito de as pessoas "[...] fazerem suas escolhas existenciais básicas e de tomarem as próprias decisões morais a propósito do rumo de sua vida." No caso em análise, a autonomia "[...] é o poder [da mulher] de controlar o próprio corpo e de tomar as decisões a ele relacionadas, inclusive a de cessar ou não uma gravidez." (BRASIL, 2016, p. 17).

A criminalização viola, ainda, o direito à integridade física e psíquica da mulher (CF, art. 5, caput e III), porque a continuidade de uma gravidez indesejada provoca ou pode provocar danos ou riscos de danos à saúde física e psíquica da mulher. No plano físico, há, no mínimo, as transformações indesejadas do corpo. No plano psíquico, há a “[...] assunção de uma obrigação para toda a vida, exigindo renúncia, dedicação e comprometimento profundo com outro ser." (BRASIL, 2016, p. 18).

A criminalização viola os direitos sexuais e reprodutivos da mulher. $\bigcirc$ ministro Luís Roberto Barroso não reporta esse fundamento a nenhum dispositivo constitucional ou legal do sistema jurídico brasileiro. Toma como referência a definição de direitos reprodutivos do Relatório da Conferência do Cairo (Capítulo VII):

$\int 7.3$ Esses direitos se baseiam no reconhecido direito básico de todo casal e de todo indivíduo de decidir livre e responsavelmente sobre o número, o espaçamento e a oportunidade de seus filhos e de ter a informação e os meios de assim o fazer, e o direito de gozar do mais alto padrão de saúde sexual e de reprodução. Inclui também seu direito de tomar decisões sobre a reprodução, livre de discriminação, coerção ou violência, conforme expresso em documentos sobre direitos humanos. ${ }^{8}$

A criminalização viola a igualdade de gênero, porque desequipara de forma injustificada mulheres e homens. Segundo essa perspectiva, "Na medida em que é a mulher que suporta o ônus integral da gravidez, e que o homem não engravida, somente haverá igualdade plena se a ela for reconhecido o direito de decidir acerca da sua manutenção ou não." (BRASIL, 2016, p. 20).

Por fim, a criminalização viola a igualdade social (BRASIL, 2016, p. 20-21). A incidência de normas penais na hipótese de interrupção voluntária de gravidez no primeiro semestre afeta, de forma desproporcional, as mulheres pobres. Por causa de sua condição socioeconômica, não conseguem ter acesso a médicos e clínicas particulares. E quando conseguem, são clínicas clandestinas que oferecem serviços médicos em condições precárias, com elevados riscos de danos e até mesmo de óbito. Se não criminalizado fosse, as mulheres pobres poderiam ter acesso a procedimentos realizados pelo

8 Sobre a Conferência do Cairo, ver Nações Unidas (1994). 
sistema único de saúde. Com a criminalização, o Estado expõe as mulheres pobres a procedimentos médicos inseguros.

\subsection{Criminalização do aborto no primeiro trimestre da gestação e princípio da proporcionalidade}

O objetivo da criminalização do aborto é a proteção da vida do feto. No entanto, segundo o ministro Luís Roberto Barroso, deve-se verificar se as restrições aos direitos fundamentais das mulheres (anteriormente citados), no caso do primeiro trimestre de desenvolvimento da gravidez, com o objetivo de proteção da vida do feto, resistem ao exame de proporcionalidade. Esse exame é composto pelo teste de adequação, teste de necessidade e teste de proporcionalidade em sentido estrito. Para o ministro, a resposta é negativa.

No exame de adequação, verifica-se se a restrição contribui, empiricamente, para o alcance do fim pretendido. A partir de estudos internacionais, o ministro Luís Roberto Barroso conclui que os índices de aborto são praticamente os mesmos em países em que a prática é ilegal e em países em que a prática é legal. Logo, a criminalização não reduz o cometimento de abortos. "Ao contrário, enquanto a taxa anual de abortos em países onde o procedimento pode ser realizado legalmente é de 34 a cada 1 mil mulheres em idade reprodutiva, nos países em que o aborto é criminalizado, a taxa sobe para 37 a cada 1 mil mulheres", afirma o ministro apoiando-se em informações do Guttmacher Institute (2016).

A criminalização afeta os abortos seguros, tendo pouco impacto sobre os abortos inseguros. Assim, não coíbe de forma adequada e eficaz a prática do aborto. Logo, a criminalização não é eficaz, ao menos na medida esperada ou desejável, para proteger o direito à vida do feto.

No exame de necessidade, o ministro Luís Roberto Barroso conclui que há meios alternativos que são menos restritivos aos direitos fundamentais das mulheres do que a intervenção penal e que são mais eficazes para alcançar o fim pretendido, a saber, proteger a vida do feto. Argumenta que meios alternativos à criminalização do aborto no primeiro trimestre são adotados em vários países do mundo. "É assim, por exemplo, na Alemanha, em que a grávida que pretenda abortar deve se submeter a uma consulta de aconselhamento e a um período de reflexão prévia de três dias."

ministro ainda enfatiza a criação de uma rede de proteção social como alternativa à adoção do direito penal no enfrentamento do problema:

Além disso, o Estado deve atuar sobre os fatores econômicos e sociais que dão causa à gravidez indesejada ou que pressionam as mulheres a abortar. As duas razões mais comumente invocadas para o aborto são a impossibilidade de custear a criação dos filhos e a drástica mudança na vida da mãe (que a faria, e.g., perder oportunidades de carreira). Nessas situações, é importante a existência de uma rede de apoio à grávida e à sua família, como o acesso à creche e o direito à assistência social. Ademais, parcela das gestações não programadas está relacionada à falta de informação e de acesso a métodos contraceptivos. Isso pode ser revertido, por exemplo, com programas de planejamento familiar, com a distribuição gratui- 
ta de anticoncepcionais e assistência especializada à gestante e educação sexual. Logo, a tutela penal também dificilmente seria aprovada no teste da necessidade. (BRASIL, 2016, p. 25).

Considerando que a criminalização do aborto voluntário no primeiro trimestre da gravidez é uma grave intervenção em diversos direitos fundamentais da mulher e que essa criminalização do aborto promove um grau reduzido de proteção aos direitos do feto (porque não causa a redução dos índices de abortos), o ministro conclui que as desvantagens da criminalização são em maior número e mais expressivas que as vantagens. Os custos superam os benefícios. Assim, a criminalização também não é aprovada no exame da proporcionalidade em sentido estrito, também chamado de ponderação de bens.

Toda a argumentação e fundamentação do ministro Luís Roberto Barroso se refere à criminalização do aborto voluntário no primeiro trimestre de gestação. Para além desse período de gestação, o ministro registra que

É preciso reconhecer, porém, que o peso concreto do direito à vida do nascituro varia de acordo com o estágio de seu desenvolvimento na gestação. O grau de proteção constitucional ao feto é, assim, ampliado na medida em que a gestação avança e que o feto adquire viabilidade extrauterina, adquirindo progressivamente maior peso concreto. (BRASIL, 2016, p. 26).

\section{Apontamentos críticos}

A primeira anotação crítica diz respeito à seguinte premissa adotada no voto-vista do ministro Luís Roberto Barroso: como a Constituição não define o momento inicial da vida a ser respeitada e protegida, não há solução jurídica para essa questão. A solução depende de escolhas apoiadas em fundamentos religiosos ou filosóficos.

De fato, a Constituição não define o momento inicial de respeito e proteção. Mas não é correto dizer, ao menos no Brasil, que essa definição é tão somente uma questão de escolha a partir de fundamentos religiosos ou filosóficos. No direito brasileiro, o Código Civil estabelece uma referência mais precisa do que a Constituição. Conforme o art. $2^{\circ}$, "A personalidade civil da pessoa começa do nascimento com vida; mas a lei põe a salvo, desde a concepção, os direitos do nascituro." (BRASIL, 2002, grifo nosso). Então, a questão do início da vida, para fins jurídicos de respeito e proteção, não é meramente questão dependente de escolha filosófica ou religiosa.

Nenhum dos ministros fez referência a esse dispositivo legal. Se de um lado é verdade que o poder constituinte originário não foi explícito sobre o momento de início da tutela constitucional da vida, de outro o poder legislativo ordinário expressamente estabeleceu que os direitos do nascituro estão protegidos pela lei desde a concepção. Portanto, a lei civil protege os direitos do nascituro inclusive no primeiro trimestre de gestação. 
Some-se a isso a previsão do direito a alimentos gravídicos disciplinado pela Lei n. 11.804, de 05 de novembro de 2008. Conforme o art. $2^{\circ}$ dessa Lei,

Os alimentos de que trata esta Lei compreenderão os valores suficientes para cobrir as despesas adicionais do período de gravidez e que sejam dela decorrentes, da concepção ao parto, inclusive as referentes a alimentação especial, assistência médica e psicológica, exames complementares, internações, parto, medicamentos e demais prescrições preventivas e terapêuticas indispensáveis, a juízo do médico, além de outras que o juiz considere pertinentes. (BRASIL, 2008, grifo nosso).

Portanto, conforme a Lei, os alimentos gravídicos são devidos desde a concepção.

Essa primeira anotação crítica conduz a uma segunda questão: a configuração jurídico-dogmática do caso. Há duas hipóteses de configuração. Primeira: se aceita a premissa de que até a décima segunda semana de gestação não há vida a ser juridicamente tutelada, então não há que se falar em colisão de direitos fundamentais. Nessa hipótese, não há uma colisão entre os direitos constitucionais do feto com os direitos fundamentais da gestante. Somente os direitos da mulher estão em jogo. Trata-se, assim, de um caso de simples interpretação (delimitação) e aplicação dos direitos fundamentais da mulher.

Em uma segunda hipótese, admitida a interpretação de que a proteção constitucional incide desde a concepção ou fecundação, configura-se uma típica colisão de direitos fundamentais. A solução depende, então, de um sopesamento dos direitos fundamentais colidentes, apurando o peso de cada um deles, dando-se prevalência a um ou a uns em detrimento de outro(s).

Quanto à configuração do caso, no voto-vista condutor do ministro Luís Roberto Barroso, parece haver uma ambiguidade. De um lado, o ministro aceita a premissa de que "[...] não há qualquer possibilidade de o embrião subsistir fora do útero materno nesta fase [primeiro trimestre] de sua formação. Ou seja: ele dependerá integralmente do corpo da mulher." (BRASIL, 2016, p. 17). Uma implicação dessa premissa é de que não há vida autônoma a tutelar juridicamente no decorrer do primeiro trimestre da gestação, ou então que há apenas uma expectativa de que venha a existir vida autônoma a tutelar. Isso se reflete no voto do ministro. Ele dá, no primeiro bloco de argumentos substantivos de sua fundamentação, ênfase exclusivamente aos direitos fundamentais da mulher. Contudo, na segunda parte de sua fundamentação, faz os três exames ou testes do princípio da proporcionalidade. Ao aplicar esse princípio, reconhece que há uma colisão de direitos fundamentais. Ou seja, reconhece que antes do fim do terceiro trimestre de gestação, há um direito à vida constitucionalmente tutelado, embora com menor "peso" que os direitos da gestante.

Evidentemente, pode-se chegar ao mesmo resultado ou conclusão em uma ou em outra configuração jurídico-dogmática do caso: inconstitucionalidade da criminalização do aborto voluntário no primeiro trimestre de gestação. A diferença reside no aspecto metódico: na segunda configuração (colisão de direitos fundamentais), aplica-se o princípio da proporcionalidade, com o consequente ônus de argumentação no exame de ponderação ou sopesamento. 
Essas duas considerações expostas indicam que um debate mais profundo poderia e deveria ter sido realizado sobre o status jurídico do feto nos primeiros três meses de gestação. É uma questão a ser enfrentada com mais rigor e profundidade no julgamento da ADPF 442.

Uma terceira anotação refere-se aos direitos fundamentais da mulher em jogo. $O$ ministro Luís Roberto Barroso, no que foi acompanhado pelos ministros Luiz Edson Fachin e Rosa Weber, apresenta um leque amplo de direitos subjetivos constitucionais violados pela criminalização da interrupção voluntária da gravidez nos primeiros três meses. São os direitos tradicionalmente citados no acirrado debate sobre o tema que ocorre há décadas, em todo mundo, nos campos jurídico, político e ético. Fazem-se aqui breves considerações sobre dois desses direitos.

Apontou-se no acordão a violação aos direitos sexuais e reprodutivos da mulher. Como referência, citou-se a definição de direitos sexuais reprodutivos do Relatório da Conferência do Cairo ( $\int 3^{\circ}$ do item 7). Porém, nenhuma fundamentação jurídico-constitucional específica foi apontada e desenvolvida. Aqui há um déficit de fundamentação. Isso não significa que não haja uma fundamentação jurídico-constitucional para o reconhecimento de direitos sexuais reprodutivos como direitos fundamentais. Primeiramente, pode-se deduzir esse reconhecimento a partir do próprio direito fundamental geral de liberdade (CF, art. $5^{\circ}$, caput). Em segundo lugar, uma fundamentação mais específica encontra amparo no $\int 7^{\circ}$ do art. 226: "Fundado nos princípios da dignidade da pessoa humana e da paternidade responsável, o planejamento familiar é livre decisão do casal, competindo ao Estado propiciar recursos educacionais e científicos para o exercício desse direito, vedada qualquer forma coercitiva por parte de instituições oficiais ou privadas." (BRASIL, 1988, grifo nosso). O conceito de livre planejamento familiar compreende o reconhecimento de direitos sexuais reprodutivos, tanto como direito de defesa do indivíduo contra interferências injustificadas do Estado, quanto como direitos à proteção e a prestações em sentido estrito.

O ministro Luís Roberto Barroso argumenta que a criminalização do aborto na hipótese em análise viola a igualdade de gênero. A argumentação desenvolvida é genérica e insuficiente. Para caracterizar a violação, não basta argumentar que

Há, por exemplo, uma visão idealizada em torno da experiência da maternidade, que, na prática, pode constituir um fardo para algumas mulheres. Na medida em que é a mulher que suporta o ônus integral da gravidez, e que o homem não engravida, somente haverá igualdade plena se a ela for reconhecido o direito de decidir acerca da sua manutenção ou não.

Que apenas mulheres engravidam é um dado da natureza e não um dado social e cultural construído. Assim, por óbvio, a criminalização do aborto, em qualquer hipótese, terá por destinatário principal a mulher. Logo, a violação ao princípio da igualdade somente seria afastada se a prática do aborto fosse permitida a qualquer tempo da gestação.

Além disso, para sustentar a tese de que a criminalização do aborto constitui uma forma de subordinação das mulheres aos homens e, por conseguinte, uma forma de estratificação entre 
homens e mulheres, são necessárias demonstrações empíricas baseadas em evidências e não apenas em genéricas afirmações. Aqui, não se está a dizer que essas evidências não existam, mas que uma fundamentação rigorosa as exige.

\section{Desdobramentos nos planos judicial e político-legislativo}

O HC 124.306 foi processado e julgado por uma das turmas do STF, e a questão constitucional foi suscitada em controle incidental. Não tem, assim, a representatividade de uma decisão do Plenário nem os efeitos erga omnes e vinculantes de uma decisão em controle de constitucionalidade por via de ação direta. No entanto, para além dos limites do HC 124.306, a decisão da Primeira Turma já impactou os planos da agenda judicial e da agenda político-legislativa. O debate jurídico e político sobre o aborto no Brasil ganhou um novo impulso.

O julgamento do referido HC foi finalizado em 09 de agosto de 2016. Sete meses depois, precisamente em 08 de março de 2017, o Partido Socialismo e Liberdade (PSOL) ajuizou a ADPF 442. No mérito, o PSOL requer que o STF declare, com eficácia geral e efeito vinculante,

a não recepção parcial [pela Constituição da República Federativa do Brasil] dos art. 124 e 126 do Código Penal, para excluir do seu âmbito de incidência a interrupção da gestação induzida e voluntária realizada nas primeiras 12 semanas, por serem incompatíveis com a dignidade da pessoa humana e a cidadania das mulheres e a promoção da não discriminação como princípios fundamentais da República, e por violarem direitos fundamentais das mulheres à vida, à liberdade, à integridade física e psicológica, à igualdade de gênero, à proibição de tortura ou tratamento desumano ou degradante, à saúde e ao planejamento familiar, de modo a garantir às mulheres o direito constitucional de interromper a gestação, de acordo com a autonomia delas, sem necessidade de qualquer forma de permissão específica do Estado, bem como garantir aos profissionais de saúde o direito de realizar o procedimento. (BRASIL, 2017).

Os fundamentos e os argumentos expostos na petição inicial da ADPF 442 são os mesmos do voto-vista do ministro Luís Roberto Barroso. O pedido coincide com a decisão da Primeira Turma. A pretensão é dar eficácia geral e efeitos vinculantes ao teor daquela decisão.

A ADPF 442 é uma ação ou um movimento que vem ao encontro da decisão da Primeira Turma do STF.

No plano legislativo, há um movimento de reação, que vem de encontro à decisão da Primeira Turma do STF e pretende se antecipar à eventual decisão de procedência na ADPF 442. Trata-se da PEC 181/2015 com a apensação da PEC 58/2011.

O texto original da PEC 181/2015, do Senado Federal, propunha a alteração da redação do inciso XVIII do art. $7^{\circ}$ da Constituição da República Federativa do Brasil (BRASIL, 2015). Em caso de aprovação, o dispositivo passaria a ter a seguinte redação: "licença à gestante, sem prejuízo do emprego e do salário, com duração de cento e vinte dias, estendendo-se a licença maternidade, em 
caso de nascimento prematuro, à quantidade de dias de internação do recém-nascido, não podendo a licença exceder a duzentos e quarenta dias."

O objetivo da proposição original é ampliar a extensão do prazo da licença maternidade na hipótese de nascimento prematuro. Trata-se de ampliar direitos das mulheres.

A PEC 58/2011, da Câmara dos Deputados, também tinha por objetivo alterar a redação do inciso XVIII do art. $7^{\circ}$ (BRASIL, 2011b). Estendia a licença maternidade, na hipótese de nascimento prematuro, "à quantidade de dias que o recém-nascido passar internado."

Em 26 de maio de 2017, a Presidência da Mesa Diretora da Câmara dos Deputados determinou, em razão da correlação de matérias, que a Comissão Especial, destinada a proferir parecer à PEC 58-A/2011, apensasse a PEC 58/2011 à PEC 181/2015. Determinou, ainda, que a Comissão Especial, inicialmente destinada a emitir parecer à PEC 58/2011, se destinasse agora a apreciar a PEC 181/2015, oriunda do Senado Federal.

Em 08 de novembro de 2017, a Comissão Especial emitiu parecer favorável (18 votos a favor e um contra) ao substitutivo às propostas de emenda à Constituição n. 181-A/2015 e de n. 58A/2011 (BRASIL, 2011a). O substitutivo mantém a redação da PEC 181/2015 do Senado Federal e dá nova redação ao inciso III do art. $1^{\circ}$ e do caput do art. $5^{\circ}$ da Constituição Federal.

O Substitutivo propõe a seguinte redação para o inciso III do art. 10: "dignidade da pessoa humana, desde a concepção." A nova redação do caput do art. $5^{\circ}$ seria esta: "Todos são iguais perante a lei, sem distinção de qualquer natureza, garantindo-se aos brasileiros e aos estrangeiros residentes no País a inviolabilidade do direito à vida desde a concepção, à liberdade, à igualdade, à segurança e à propriedade [...]" (BRASIL, 1988, grifo nosso).

No parecer aprovado pela Comissão Especial, o relator deputado Jorge Tadeu Mudalen indica claramente que o objetivo da PEC 181-A/2015 é bloquear o denominado ativismo judicial do STF. Embora não faça referências nominais à ADPF 54 (anencefalia) (SUPREMO TRIBUNAL FEDERAL, 2012) e ao HC 124.306, o parecer credita ambas as decisões ao ativismo do STF. O relator invoca o Estado de Direito, a separação dos poderes e as competências do parlamento para a matéria.

O ajuizamento da ADPF 442 e o parecer favorável da Comissão Especial da Câmara dos Deputados à PEC 181-A são evidências de que a decisão da Primeira Turma do STF no HC 124.306 ganhou um sentido e um alcance que transcenderam os limites do próprio caso decidido. A decisão repôs na agenda judicial e política do País o controverso tema da descriminalização do aborto para além das hipóteses previstas no Código Penal e na ADPF 54. A decisão da Primeira Turma do STF, deliberadamente ou não, cumpriu um papel estratégico para impulsionar o enfrentamento de um tema controverso em todo o mundo, mas que em muitos países foi resolvido precisamente no mesmo sentido apontado pela decisão do STF: a não criminalização da interrupção voluntária de gravidez no primeiro trimestre. 


\section{Referências}

BRASIL. Câmara dos Deputados. Comissão Especial. Parecer Substitutivo às Propostas de Emenda à Constituição n. 181-A, de 2015 e de n. 58-A, de 2011. Disponível em: < http://www.camara.gov.br/ proposicoesWeb/prop_mostrarintegra;jsessionid=4CF5BC5DFE082842135B9F1B14B60C67.proposicoesWebExterno1 .codteor $=1586817 \&$ filename $=$ Parecer-PEC18115-16-08-2017> . Acesso em: 15 nov. 2017.

BRASIL. Câmara dos Deputados. PEC 58/2011. Disponível em: <http://www.camara.gov.br/proposicoesWeb/prop_mostrarintegra?codteor $=903246 \&$ filename $=\mathrm{PEC}+58 / 2011>$. Acesso em: 15 nov. 2017.

BRASIL. Constituição. República Federativa do Brasil de 1988. Brasília, DF: Senado Federal, 05 out. 1988.

BRASIL. Lei n. 10.406, de 10 de janeiro de 2002. Institui o Código Civil. Diário Oficial da União, 11 jan. 2002.

BRASIL. Lei n. 12.403, de 04 de maio de 2011. Altera dispositivos do Decreto-Lei n 3.689, de 3 de outubro de 1941 - Código de Processo Penal, relativos à prisão processual, fiança, liberdade provisória, demais medidas cautelares, e dá outras providências. Brasília, DF, Diário Oficial da União, 05 maio 2011.

BRASIL. Senado Federal. PEC 181/2015. Disponível em: < http://www.camara.gov.br/proposicoesWeb/prop_mostrarintegra?.codteor $=1425029 \&$ filename $=P E C+181 / 2015>$. Acesso em: 15 nov. 2017.

BRASIL. Senado Federal. Proposta de Emenda à Constituição No 181-A, DE 2015 (Apensa a PEC No 58-A, DE 2011). Altera a redação do inciso XVIII do artigo $7^{\circ}$ da Constituição Federal para dispor sobre a licença-maternidade em caso de parto prematuro. Relator: Deputado Jorge Tadeu Mudalen. Câmara dos Deputados, 2017. Disponível em: <http://www.camara.gov.br/proposicoesWeb/prop_ mostrarintegra;jsessionid =4CF5BC5DFE082842135B9F1B14B60C67. proposicoesWebExterno1 ? codteor=1586817\&filename=Parecer-PEC18115-16-08-2017>. Acesso em: 15 nov. 2017.

BRASIL. Superior Tribunal de Justiça. Habeas Corpus 290.341. Órgão Julgador: Sexta Turma. Relatora: Ministra Maria Thereza de Assis Moura. Rio de Janeiro, 13 mar. 2014. Disponível em: <http://www.stj.jus.br/SCON/decisoes/toc.jsp?.processo=290341..NUM.\&\&b=DTXT\&thesaurus $=$ JURIDICO\&p=true $>$. Acesso em: 23 out. 2017.

BRASIL. Supremo Tribunal Federal. ADPF 54. Relator: ministro Marco Aurélio. Órgão Julgador: Plenário. Julgamento em 12 abr. 2012. Brasília, DF, 14 abr. 2012. Disponível em: < http://redir.stf. jus.br/paginadorpub/paginador.jsp?docTP=TP\&docID=3707334>. Acesso em: 16 nov. 2017.

BRASIL. Supremo Tribunal Federal. Habeas Corpus 124.306. Relator: ministro Luís Roberto Barroso. Órgão Julgador: Primeira Turma. julgamento em 09 ago. 2016. Rio de Janeiro, 29 nov. 2016. Disponível em: <http://redir.stf.jus.br/paginadorpub/paginador.jsp?docTP=TP\&docID $=12580345>$. Acesso em: 23 out. 2017.

GUTTMACHER INSTITUTE. Restrictive laws do not stop women from having abortions. Disponível em: <https://www.guttmacher.org/sites/default/files/infographic_attachment/worldwideincidencerestrictive.pdf>. Acesso em: 04 out. 2017. 
NAÇÕES UNIDAS. Relatório da Conferência Internacional sobre População e Desenvolvimento - Plataforma de Cairo, 1994. Apresentação de Tania Patriota. Disponível em: <http://www.unfpa.org.br/ Arquivos/relatorio-cairo.pdf>. Acesso em: 4 nov. 2017.

PARTIDO SOCIALISMO E LIBERDADE. Arguição de Descumprimento de Preceito Fundamental 442. Petição inicial. Disponível em: <https://www.conjur.com.br/dl/psol-stf-descriminalize-aborto-meses.pdf>. Acesso em: 23 out. 2017.

SUPREMO TRIBUNAL FEDERAL. ADPF n. 442. Brasília, DF, 06 mar. 2017. Disponível em: < https://www.conjur.com.br/dl/psol-stf-descriminalize-aborto-meses.pdf>. Acesso em: 04 nov. 2017.

Data de submissão: 22 de novembro de 2017. Aceito em: 08 de dezembro de 2017. 